DOI 10.1515/linpo-2016-0009

\title{
Universals of causative and anticausative verb formation and the spontaneity scale
}

\author{
Martin Haspelmath \\ Department of Linguistic and Cultural Evolution, \\ Max Planck Institute for the Science of Human History \\ Institut für Anglistik, Leipzig University \\ e-mail: haspelmath@shh.mps.de
}

\begin{abstract}
Martin Haspelmath. Universals of causative and anticausative verb formation and the spontaneity scale. The Poznań Society for the Advancement of Arts and Sciences, PL ISSN 0079-4740, pp. 33-63

In this paper, I formulate and explain a number of universal generalizations about the formation of causative verbs (overtly marked verbs with causal meaning) and anticausative verbs (overtly marked verbs with noncausal meaning). Given the "spontaneity scale" of basic verb meanings (transitive $>$ unergative $>$ automatic unaccusative $>$ costly unaccusative $>$ agentful), we can say that verb pairs with a noncausal verb higher on the scale tend to be causative pairs, and verb pairs with a noncausal verb lower on the scale tend to be anticausative pairs. I propose that these generalizations can be subsumed under form-frequency correspondence: That transitive base verbs tend to form causatives (often analytic causatives) is because they rarely occur in causal contexts, and the fact that unaccusative verbs tend to be coded as anticausatives is because they frequently occur in causal contexts, and special marking is required for the rarer and less expected situation.
\end{abstract}

Keywords: causative verb, linguistic universal, spontaneity scale, transitivity, form-frequency correspondence

\section{Introduction}

In this paper, I propose a unification of a number of cross-linguistic generalizations about the distribution of causative, anticausative and basic verb forms, as well as an explanation of the universals as an instance of the extremely widespread phenomenon of form-frequency correspondence (Haspelmath 2018a). The fundamental idea is that explicitness of coding is functionally motivated by lower expectedness, which is often a consequence of low frequency of use.

The example verb pairs in (1) give a preview of the kinds of phenomena that I will discuss here. For each of the four languages, we see two verb pairs (with a noncausal and a corresponding causal verb) showing different kinds of noncausal-causal alternation, generally with asymmetrical grammatical coding (shown in boldface), whose distribution 
depends on the type of meaning of the noncausal member of the verb pair (and ultimately on predictability, as will be seen in $\S 8$ ).

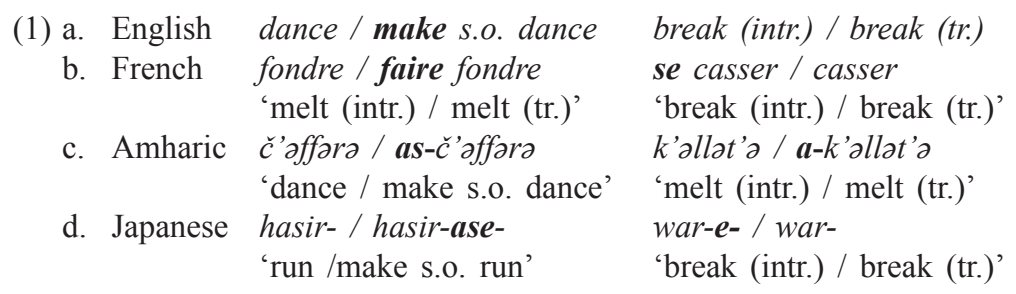

I will claim in this paper that the occurrence of causative and anticausative verb forms follows a regularity that can be formulated in terms of the "spontaneity scale" of noncausal verb meanings in (2). The five types of meanings of this scale will be characterized below in $\$ 2$; here I just give one sample meaning (in parentheses below each type label) to give a first idea of the intended kinds of verb meanings. (The name "spontaneity scale" for this scale will be explained at the end of $\S 2$.)

(2) the spontaneity scale

$\begin{aligned} & \begin{array}{l}\text { transitive } \\ \text { ('cut') }\end{array} \\ & <\begin{array}{l}\text { unergative } \\ \text { ('talk') }\end{array}\end{aligned}$
$<$ more causatives

In simplified terms, the basic generalization (laid out in $\S 4$ ) is that causative coding, especially analytic coding, of a verb pair is more likely when the noncausal verb's meaning is on the higher end (the left-hand part) of the scale, while anticausative coding is more likely when the noncausal verb's meaning is on the lower end (the right-hand part) of the scale. Basic (non-derived) verbs (with either a causal or a noncausal meaning) are most likely to occur in the middle of the scale. Thus, to express the idea of 'making someone talk', and especially 'making someone cut something', languages are quite likely to use causatives, often analytic causatives. To express the idea of 'breaking (intr.)' and especially 'being cut', languages are quite likely to use anticausatives, i.e. forms with special coding that indicates a non-causal meaning.

The spontaneity scale thus allows us to make precise predictions about the types of verb forms that are used in the world's languages to code verb pairs with causal and noncausal meanings (see §5-6). Languages exhibit quite a variety of patterns, but we will see that there are strict limits on the attested diversity. Speaking in absolute terms, no language has a simple verb root meaning 'make someone cut something', and (almost) no language has a simple verb root meaning 'be cut' (\$7). The implicational generalizations are even stronger: No language that requires an analytic causative to express 'make someone talk' will have a synthetic causative for 'make someone cut something'. And if a language has a causative to express 'break (tr.)', it is very likely that it will also have a causative to express 'freeze (tr.)', though not the other way round. In $\S 8$, I propose an 
explanation of these generalizations in terms of form-frequency correspondence, and I discuss a number of related proposals.

\section{The five semantic types of verb meanings}

Before presenting the cross-linguistic generalizations in detail and with examples, I need to characterize the five semantic types of verb meanings of the spontaneity scale. We will see in $\S 8$ that the ultimate explanation of the generalizations is not in semantic terms, but in terms of expectedness (or predictability) and coding efficiency. However, for expository purposes, for purposes of cross-linguistic validation, and in order to relate my claims to the earlier literature, I find it expedient to formulate them in these semantic terms at this stage.

TRANSITIVE verb meanings are verb meanings where an agent impinges directly on a patient, especially in a physical way ('break', 'kill', 'lift', etc.). A precise delimitation of 'transitive' is not necessary here, because the primary claim concerns the cross-linguistic tendencies of coding, and a core of transitive verbs is generally easy to identify in any language. All languages also have a number of less typical transitive verbs (see Lazard 2002; Haspelmath 2015a), and these mostly behave like the typical transitives, also with respect to causative behaviour, but my claim primarily concerns core transitive verb meanings.

The term UnERgative (originally from the syntactic literature, cf. Perlmutter 1978) has come to be used widely also in a (quasi-)semantic sense and is used here as an abbreviation of 'agentive intransitive', i.e. verb meanings like 'talk', 'work', 'walk', 'play', or 'scream'. These are verb meanings referring to (typically volitional) human actions that are not directed specifically at another participant and that have no inherent limit.

Unergative verbs are often contrasted with UNACCUSATIVE verbs, i.e. intransitive verbs with non-agentive meanings implying changes of state, typically of inanimate participants, e.g. 'melt', 'freeze', 'boil', 'die', 'fall', 'dry up', 'split', 'break'. Like unergative, the term unaccusative originally has a syntactic definition, but it is very often associated with verb meaning (e.g. Levin \& Rappaport Hovav 1995) because the groups of verbs that tend to fall into these syntactic classes are typically semantically coherent. ${ }^{1}$

Unaccusative verb meanings are divided into two classes here, AUTOMATIC and COSTLY verb meanings. These two classes are not found in the earlier literature, and I readily admit that they are somewhat ad hoc and are introduced here primarily for expository purposes. Briefly, an automatic process is a process that is easily construed as occurring on its own, without any external energy input, such as 'melt', 'freeze', 'dry', 'wake up', 'sink', 'go out (fire)'. A costly process is a process that does not so easily occur on its own, but typically involves some energy input (“cost”), e.g. 'break (intr.)', 'split (intr.)',

${ }^{1}$ In earlier versions of this work (various conference presentations and summer school lectures since 2005), I used the terms agentive and patientive (for unergative and unaccusative) because they are more transparent. The terms unergative and unaccusative (for 'intransitive agentive' and 'intransitive patientive') are nontransparent (syntax-derived), but they are preferred here because they are shorter and more convenient. 
'open (intr.)', 'close (intr.)', 'change (intr.)', 'gather (intr.)'. The contrast between these two subclasses of unaccusatives is not nearly as salient as the contrast between unergatives and unaccusatives, which corresponds to coding differences in many languages. The contrast between automatic and costly verb meanings emerged from a typological study of causal-noncausal alternations (Haspelmath 1993: §7), and I do not want to suggest that it can be seen as a categorical contrast, nor even that there is an easily identifiable core (as there is with transitives) in either of the two types. Thus, until more research is done and more evidence is found, I limit my claims to the twelve sample meanings given above.

Finally, AGENTFUL is an ad hoc term used here for (potential) verb meanings that refer to processes such as 'be cut', 'be washed', 'be beaten', 'be thrown' which are quite difficult to construe as occurring on their own, without an agent, because of agent-oriented manner components in their meaning (i.e. they seem to require reference to an agent in their definition). ${ }^{2}$ In this regard, these verb meanings are quite different from unaccusatives such as 'melt', 'sink', 'break (intr.)' and 'change (intr.)'. We can easily talk about wax melting, a boat sinking, a stick breaking, and a person changing without thinking of an agent, but when we talk about cutting, washing and throwing, we seem to necessarily have an agent in mind. Note that when I refer to agentful verb meanings, I mean the intransitive version, i.e. 'be cut' rather than 'cut', and 'be thrown' rather than 'throw' (the latter are straightforward transitive actions including an agent). The agentful verb meanings, by contrast, are intransitive processes that do not include an agent even though it is not easy to think of these processes without an agent.

Table 1 gives an overview of the five types of verb meanings on the spontaneity scale.

Table 1: Five types of verb meanings on the spontaneity scale: Some examples

\begin{tabular}{|c|c|c|c|c|}
\hline \multirow{2}{*}{$\begin{array}{c}\text { Transitive } \\
\text { (most spontane- } \\
\text { ous) }\end{array}$} & \multirow{2}{*}{ Unergative } & \multicolumn{2}{|c|}{ Unaccusative } & \multirow{2}{*}{$\begin{array}{c}\text { Agentful } \\
\text { (least spontane- } \\
\text { ous) }\end{array}$} \\
\hline & & Automatic & Costly & \\
\hline $\begin{array}{l}\text { 'cut', 'wash', } \\
\text { 'throw', 'eat', } \\
\text { 'hit', 'see' }\end{array}$ & $\begin{array}{l}\text { 'talk', 'dance', } \\
\text { ‘walk', 'play', } \\
\text { ‘work', 'scream' }\end{array}$ & $\begin{array}{l}\text { 'melt', 'freeze', } \\
\text { 'dry', 'wake up', } \\
\text { 'sink', 'go out } \\
\text { (fire)' }\end{array}$ & $\begin{array}{l}\text { 'break (intr.)', } \\
\text { 'split (intr.)', } \\
\text { 'open (intr.)', } \\
\text { 'close (intr.)', } \\
\text { 'change (intr.)', } \\
\text { 'gather (intr.)' }\end{array}$ & $\begin{array}{c}\text { 'be cut', 'be } \\
\text { washed', 'be } \\
\text { thrown', 'be } \\
\text { eaten', 'be hit', } \\
\text { 'be seen' }\end{array}$ \\
\hline
\end{tabular}

I find it helpful to say that the spontaneity scale has to do with likelihood of spontaneous occurrence: While agentful processes are very unlikely to occur spontaneously (without an extra causer causing them), costly processes are somewhat more likely to do

${ }^{2}$ Haspelmath (1993: 94) and Hale \& Keyser (1993: 90) noted that in English, verbs can be used both as causals (he breaks it) and as noncausals (it breaks) only if the verb has no agent-oriented manner meaning components. Thus, agentful meanings need to be expressed as passive verbs in English (it is cut, not *it cuts) and in many other languages (but not in all languages; see §7). 
so, and automatic processes even more so (Haspelmath 1993: 105). With unergative and transitive actions, the degree of spontaneity is of course still higher, so much so that non-spontaneous occurrence (with an outsider causer) seems quite unlikely especially for transitive actions. But this intuitive characterization of "spontaneity" is not meant as a serious semantic analysis, but only as a motivation for choosing the mnemonic term spontaneity scale; we will see below in $\S 8$ that what ultimately underlies the scale generalizations is not any semantic concept, but a usage-based generalization. Thus, I do not explain "spontaneity" any further here, and readers who do not find this term helpful can rename the scale in (2) for themselves (e.g. "s-scale"). ${ }^{3}$

\section{Some terminology}

Before I can present the universals, I need to clarify some key comparative concepts. The most important pair of terms is CAUSATIVE and anticausative: I follow the older literature (Nedjalkov \& Sil'nickij 1969; Haspelmath 1987; also Haspelmath et al. 2014) in using causative for causal verbs with special coding (e.g. Turkish öl-dür- [die-CAus-] 'kill'), and anticausative for noncausal verbs with special coding (e.g. Russian lomat'-sja [break-ANTICAUS] 'break (intr.)'). Some examples of both types are given in (3) and (4).

a. Turkish
b. Japanese
c. Lithuanian

a. Russian

b. Hebrew

c. Swahili basic verb (noncausal meaning)

öl- 'die' kawak-u 'dry (intr.)' deg-ti 'burn (intr.)'

basic verb (causal meaning) otkryt' 'open (tr.)' picel 'split (tr.)' vunj-a 'break (tr.)' causative verb (with special coding) (causal meaning)

öl-dür- 'kill' (= 'make die')

kawak-as-u 'dry (tr.)' (= 'make dry')

deg-in-ti 'burn (tr.)' (= 'make burn')

anticausative verb (with special coding) (noncausal meaning)

otkryt'-sja 'open (intr.)'

hit-pacel 'split (intr.)'

vunj-ik-a 'break (intr.)'

Confusingly, these terms are sometimes used in a semantic sense in the literature (as when English break is said to occur in a "causative use" and in an "anticausative use"), but in this paper the semantic contrast is described by the clearer terms CAUSAL and NONCAUSAL. The term noncausal comprises what has sometimes been called "inchoative" (as in the older term causative-inchoative alternation for verbs like break, e.g. Haspelmath 1993), but it is used in a much broader sense here, for any verb meaning that contrasts

\footnotetext{
${ }^{3}$ Two colleagues have expressed the intuition that processes like 'melt' are more spontaneous than transitive processes like 'cut', contrary to the scale. This intuition seems to come from the fact that volitional actions are not normally talked about in terms of spontaneity, because it seems so far-fetched that they could be non-spontaneous (i.e. caused by some other process). However, this is precisely my point: Transitive processes are so spontaneous that this goes without saying (and we don't need causative marking). For readers who are interested in thinking more about the semantics and ontology of spontaneity and entropy, I can recommend Kulikov (1998b) and Howard (2001).
} 
with a causal verb meaning and lacks its 'cause' component. Thus, break (intr.) is noncausal when compared to break (something), but break something is noncausal when compared to make someone break something. ${ }^{4}$ Note also that cut is regarded as the causal counterpart of be cut.

For verb pairs that make no formal difference between the causal and the noncausal use (e.g. break, in 1a), I use the term LABILE.

The term VERB FORM is used in a very broad sense, to refer to any (analytic, synthetic or root) form that can express a verbal meaning. The difference between inflection and derivation, or between morphology and syntax is irrelevant here. The distinction between analytic and synthetic verb forms can be thought of in orthographic terms for the moment (see $\S 8.1$ on the way in which I use the terms analytic/synthetic).

\section{Implicational universals of causative and anticausative verb formation}

The two basic observations that I will eventually derive from form-frequency correspondence are the universals in (5) and (6). They are formulated in a maximally general way, as numbered Greenberg-style implicational universals. Interestingly, they are perfect mirror images of each other, and this will be explained in $\S 8$ below.

Universal 1

The HIGHER the noncausal meaning of a causal-noncausal pair is on the spontaneity scale, the longer and the more analytic any CAUSATIVE marker on the CAUSAL verb form will be.

(6) Universal 2

The LOWER the noncausal meaning of a causal-noncausal pair is on the spontaneity scale, the longer and the more analytic any ANTICAUSATIVE marker on the NONCAUSAL verb form will be.

The illustrations in this paper will not involve degrees of analyticity (e.g. clitic vs. free auxiliaries), or more than two kinds of synthetic causative markers (short markers and long markers), or more than one kind of synthetic anticausative marker, but there is no reason why Universals 1 and 2 should be formulated in a less general way. For example, if a language had three or four different synthetic (anti)causative markers, or two different synthetic anticausative markers, they would still be predicted to pattern according to the universals, with length determined by the position of the noncausal meaning on the spontaneity scale. I have not come across examples of such languages, but eventually we may well find languages that make more fine-grained distinctions. (Universals 1 and 2 say nothing about the number of distinctions that a language may have, and the additional universals to be formulated below in (41) do not make such claims either. I take it to be an accident that I have not found any languages with more than four different alternation types so far.)

\footnotetext{
${ }^{4}$ Nichols et al. (2004) us the term pair induced/plain for what I call causal/noncausal.
} 
Thus, for practical purposes I will distinguish six kinds of causal-noncausal alternations, as listed in (7a-f), with one example of each. ${ }^{5}$
a. (causative pair) English
analytic causative (anaC)
make s.o. believe
basic noncausal
believe
b. (causative pair) Japanese
long causative $(\lg \mathrm{C})$
hasir-ase-
'make s.o. run'
basic noncausal
hasir-
'run'
c. (causative pair) Japanese
short causative (shC)
kawak-as-
'dry (tr.)'
basic noncausal
kawak-
'dry (intr.)'
d. (labile pair)
English
basic causal
break (tr.)
basic noncausal
break (intr.)
e. (anticausative pair) basic causal
Russian
otkryt'
'open (tr.)'
anticausative (A)
otkryt'-sja
'open (intr.)'
f. (anticausative pair) basic causal Lezgian
$x k a z ̌-u n$
'raise'
analytic anticausative (anaA)
xkaž $\hat{x} u n$
'rise'

Given these six categories, ${ }^{6}$ we can say that the causative-anticausative coding scale in (8a) roughly corresponds to the spontaneity scale in (8b).
a. anaC $>\lg \mathrm{C}>\operatorname{shC}>$ labile $>\mathrm{A}>$ anaA
b. transitive $>$ unergative $>$ automatic $>$ costly $>$ agentful $(=2)$

But there is of course no simple one-to-one correspondence between the positions on scale (8a) and scale (8b): Analytic causatives (make s.o. believe) need not have transitive base verbs but may have intransitive base verbs as well: especially of the unergative type (make s.o. talk), but also of the unaccusative type (make s.th. melt, make s.th. change). Synthetic causatives may have transitive base verbs (e.g. (12b) below), or intransitive

${ }^{5}$ In addition to the six types in (7), there are also several types of equipollent pairs: pairs with root suppletion (like die/kill in English), alternations of equally long stems (like rise/raise in English), and cases where both members of the pair contain a formal marker (e.g. Hungarian tan-ul 'learn' / tan-it 'teach'). These verb pairs do not contain causative or anticausative markers, so no predictions are made about them here. It seems, however, that they generally behave like labile pairs (7d). Moreover, languages may also have causatives of causatives (Kulikov 1993), which often behave like causatives of transitives.

${ }^{6}$ A reviewer notes that the coding types in (7b) and (7c) are relational, i.e. they can be applied only to languages (such as Japanese) that have two different types. But note that this also applies to the types in (7a) and (7f), because the contrast between "analytic" and "synthetic" eventually boils down to a length contrast as well (see §8.1). Languages that have only a single causative or anticausative marker must be evaluated on a simpler scale $(\mathrm{C}>$ labile $>\mathrm{A})$, but this does not affect the predictions. 
base verbs of various kinds (as in (3) above). Labile verb pairs and anticausatives are also somewhat variable, though here the correspondence is tighter: Labile pairs are generally used for automatic and costly meanings (e.g. melt (tr./intr.), split (tr./intr.)), and analytic anticausatives are mostly used for agentful meanings (e.g. be cut, be eaten). But synthetic anticausatives may be used for automatic, costly and agentful meanings.

While the correspondence between the coding scale in (8a) and the spontaneity scale in (8b) is thus not absolute, it can be expressed in relative terms in implicational universals of the type in (9), which can be readily tested by further cross-linguistic research.

a. Universal 3

If an analytic causative can be used with base verbs of some type,

it can be used with base verbs of all types higher on the spontaneity scale.

b. Universal 4

If a synthetic causative can be used with base verbs of some type, analytic causatives will not be required with base verbs lower on the spontaneity scale.

c. Universal $5^{7}$

If an analytic anticausative can be used with base verbs of some type, it can be used with base verbs of all types lower on the spontaneity scale.

These universals are special cases of the primary Universals 1 and 2, using the less abstract comparative concepts of (7a-f). To make the predictions even more concrete, I will examine them one by one in the next two sections and relate them to earlier work.

\section{Causative verb forms}

\subsection{Synthetic causatives of transitives and intransitives}

Let us begin with Nedjalkov's (1966) observation that if a language allows synthetic causatives of transitives (yielding trivalent verbs), it also allows synthetic causatives of intransitives, as formulated in (10) (The Universals Archive \#285). ${ }^{8}$

\footnotetext{
7 A reviewer asks whether there is also a corresponding universal about synthetic anticausatives: "If a synthetic anticausative can be used with base verbs of some types, analytic anticausatives will not be required with base verbs higher on the spontaneity scale." The answer is yes (because Universals 1 and 2 are completely symmetrical), but there is not enough attested variation in anticausatives to exemplify this.

${ }^{8}$ Comrie (1975: 11) has an even more general formulation of this universal: "A language forms causatives from verbs with valency $n+1$ only if it forms causatives from verbs with valency $n$ " (a similar formulation is found in Nedjalkov \& Sil'nickij 1969, as pointed out by a reviewer). In practice, the only additional prediction here is that no language has causatives of ditransitives but lacks causatives of monotransitives. Since languages generally have very few ditransitive verbs, this is not a very strong claim, and few languages have been reported to have synthetic causatives of monotransitives but to lack synthetic causatives of ditransitives. Comrie (1975: 9-11) mentions Songhay, and Dixon (2000: 57) adds Basque. This is too little evidence to add "ditransitive" to the spontaneity scale at the current stage, but more evidence may become available. (Note
} 
(10) Universal 6

If a language has synthetic causatives of transitive verbs,

it also has synthetic causatives of intransitive verbs. ${ }^{9}$

This universal (probably the first universal claim about causatives in the literature) thus allows languages like Tuvan (Turkic) in (11)-(12), where both intransitive and transitive verbs can be causativized by a suffix, and also languages like (Standard) Indonesian in (13)-(15), where the marker -kan forms causatives from intransitive bases (both unaccusative and unergative), but not causatives from transitive bases (the resulting construction is a benefactive applicative, irrelevant in the present context).

Tuvan (Kulikov 1998a: 260)
a. ool doy-gan
boy freeze-PST
'The boy froze.'

b. ašak ool-du doy-ur-gan

old.man boy-ACC freeze-CAUS-PST

'The old man made the boy freeze.'

(12)
a. ašak ool-du ette-en
old.man boy-ACC hit-PST

'The old man hit the boy.'

b. Bä̈r ašak-ka ool-du ette-t-ken

Bajyr old.man-DAT boy-ACC hit-CAUS-PST

'Bajyr made the old man hit the boy.'

Indonesian (Cole \& Son 2004: examples 1, 2, 5)

(13) a. Cangkir-nya pecah.

cup-DEF break

'The cup broke.'

b. Tono me-mecah-kan cangkir-nya.

Tono ACT-break-CAUS cup-3

'Tono broke the cup.'

(14)

a. Adik saya sudah mandi.
brother 1SG already bathe
'My brother has bathed.'

also that the difficulty of forming causatives of ditransitives may have to do with the difficulty of accommodating four arguments, as discussed by Dixon 2000: 56-59.)

9 The original (fully equivalent) formulation was: "In all languages: if there are trivalent causatives derived from bivalent non-causative verbs, there must also be bivalent causatives derived from one-place non-causatives." The generalization also appears in Nedjalkov \& Sil'nickij (1969) (and Nedyalkov \& Silnitsky 1973). Later discussions include Song (1996: 170-174) and Malchukov (2016: §3). 
b. Dia me-mandi-kan adik saya.

he ACT-bathe-CAus brother I

'He bathed [= caused to bathe] my brother.'

a. Dia meng-goreng ayam untuk saya.

he ACT-fry chicken for I

'He fried chicken for me.'

b. Dia meng-goreng-kan saya ayam.

he ACT-fry-CAUS I chicken

*'He made me fry the chicken.'

(OK: 'He fried me chicken.' $)^{10}$

What does not occur is languages which have synthetic causatives from transitives, but not from intransitives. In Table 2, we see the Tuvan and Indonesian types, as well as one logically possible but unattested type. (I have not given examples of analytic causatives in Indonesian, and Cole \& Son (2004) do not provide any, but I assume that there is some analytic way of saying 'He made me fry the chicken'.) ${ }^{11}$

Table 2: Synthetic causatives: Some language types

$(\mathrm{C}=$ synthetic causative, anaC $=$ analytic causative $)$

\begin{tabular}{c|cc}
\hline & Transitive & Intransitive \\
\hline Tuvan & $\mathrm{C}$ & $\mathrm{C}$ \\
Indonesian & $($ anaC) & $\mathrm{C}$ \\
(unattested) & $\mathrm{C}$ & anaC \\
\hline
\end{tabular}

One could probably set up a verb meaning type intermediate between transitive and intransitive on the spontaneity scale: verbs of ingestion ('eat', 'drink', 'learn'), which have repeatedly been reported to allow synthetic causatives in languages that do not have causatives of transitives otherwise (Nedjalkov \& Sil'nickij 1969; Dixon 2000: 64). The main reason why I have not done this here is that the paper is already long enough.

${ }^{10}$ It is not uncommon for transitivizing markers to have a causative function with some kinds of verbs (those lower on the spontaneity scale), but an applicative function with others (those higher on the spontaneity scale). See Austin (1997) for this phenomenon in Australian languages, and Shibatani \& Pardeshi (2002: §6), as well as Malchukov (2016: §5) for further discussion.

11 It is difficult to distinguish generally between grammatical constructions with causative function and complement-taking verbs translated as 'cause', 'induce' or 'force'. Fortunately, for the purposes of the generalizations in this paper, this is not necessary. I simply assume that all languages have a way of rendering the notion of 'making s.o. do s.th.' or 'making s.th. happen' with any base verb meaning. This may be a complement-taking verb plus a complement clause, or it may even be two conjoined clauses ('He did something and I talked', for 'He made me talk'). All of these strategies can count as ,analytic causatives“ for the purposes of the generalizations of this paper. 


\subsection{Synthetic causatives of unergatives and unaccusatives}

Next, let us examine synthetic causatives of unaccusatives and unergatives. We saw that some languages allow causatives of both subtypes of intransitives (e.g. Indonesian in (13)-(14)), but there are also languages where only synthetic causatives of unaccusatives are possible, but not synthetic causatives of unergatives. For example, Hale (2000) observes that in O'odham (Uto-Aztecan), one can form causatives from verbs such as those in (16), but not from verbs such as those in (17).

O'odham (Hale 2000: 157-158)

(16) huРuñ 'descend' hu?uñ-id 'lower'

cesaj 'rise' cesaj-id 'raise'

heum 'get cold' heum-cud 'make cold'

(17) $\tilde{n} e^{\prime} \ddot{e}$ 'sing' $\tilde{n} e^{\prime} i$-cud *'make s.o. sing' ('sing for s.o.')

cikpan 'work' cikpañ-id *'make s.o. work' ('work for s.o.')

gikuj 'whistle' gikuj-id *'make s.o. whistle' ('whistle for s.o.')

Similarly, in Fijian, one can form causatives from verbs such as those in (18), but not from those in (19). ${ }^{12}$

Fijian (Dixon 1988: §18.2)

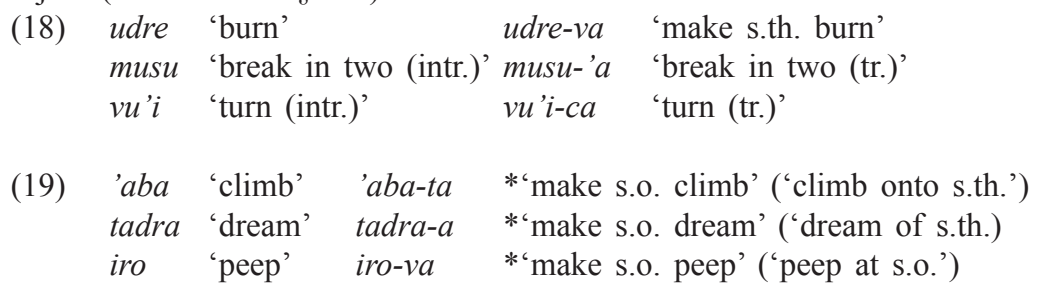

Another language for which a situation of this kind has been reported and discussed in typological perspective is Vedic Sanskrit (Kulikov 2013). We can thus formulate Universal 7, analogous to Universal 6 in (10) above.

(20) Universal 7 (first version, to be revised below)

If a language has synthetic causatives based on unergative verbs,

it also has synthetic causatives based on unaccusative verbs.

O'odham, Fijian and Vedic represent an additional type, as illustrated in Table 3 (again, I do not know how to form analytic causatives in O'odham, but I assume that

12 According to Dixon, the transitivity marker $(-\mathrm{Ca})$ has a causative sense with verbs where "it is the effect on the patient which is seen as most significant", while it has an applicative sense with verbs "where the motion or action of A is the most significant aspect of the situation spoken of". See also Kazenin (1994: $\S 3.2$ ) for further discussion. Fijian is thus quite similar to O'odham, where the causative suffix -id/-cud has an applicative sense with unergative base verbs as well. The causative-applicative polysemy here is quite similar to the analogous phenomenon with intransitive/transitive bases (cf. note 10). 
they exist, so they appear in parentheses, like the Indonesian analytic causatives). The other three types are unattested, as far as I am aware.

Table 3: Synthetic causatives: Some language types

$(\mathrm{C}=$ synthetic causative, anaC $=$ analytic causative $)$

\begin{tabular}{cccc}
\hline & $\begin{array}{c}\text { Transitive } \\
\text { ('cut') }\end{array}$ & $\begin{array}{c}\text { Unergative } \\
\text { ('talk') }\end{array}$ & $\begin{array}{c}\text { Unaccusative } \\
\text { ('freeze; break') }\end{array}$ \\
\hline Tuvan & $\mathrm{C}$ & $\mathrm{C}$ & $\mathrm{C}$ \\
Indonesian & $(\mathrm{anaC})$ & $\mathrm{C}$ & $\mathrm{C}$ \\
O'odham & $(\mathrm{anaC})$ & $(\mathrm{anaC})$ & $\mathrm{C}$ \\
\hline (unattested) & $\mathrm{anaC}$ & $\mathrm{C}$ & $\mathrm{anaC}$ \\
(unattested) & $\mathrm{C}$ & $\mathrm{C}$ & $\mathrm{anaC}$ \\
(unattested) & $\mathrm{C}$ & $\mathrm{anaC}$ & $\mathrm{C}$ \\
\hline
\end{tabular}

However, Universal 7 cannot be fully parallel to Universal 6 and needs to be amended. The reason is that the causal counterpart of unaccusatives need not be a causative: It could have the same form as the unaccusative, thus forming a labile verb pair (e.g. English break (intr./tr.), open (intr./tr.), change (intr./tr.)). Or the noncausal member of the pair could be an anticausative, corresponding to a basic causal verb (e.g. Russian slomat'-sja 'break (intr.)' / slomat' 'break (tr.)'). Thus, the universal must be formulated as in (21).

(21) Universal 7 (definitive version)

If a language has synthetic causatives based on unergative verbs,

it also has synthetic causal verbs corresponding to unaccusative noncausal verbs.

\subsection{Long and short causative markers}

As first studied by Kulikov (1993), some languages have two different causative markers, one of which is longer than the other (i.e. consists of more segments). I claim here that the distribution of the two markers reflects the spontaneity scale. There are two subtypes.

In one type of language, the choice between the two markers is conditioned by the transitivity of the base verb. Some examples are given in (22)-(26).

(22) Georgian: $a$-X-eb- vs. $a$-X-ineb- (Nedjalkov \& Sil'nickij 1969)
a. $d u \gamma^{-}$'boil (intr.)'
$\boldsymbol{a}-d u \gamma-\boldsymbol{e b}-s \quad$ 'boils (tr.)'
b. c'er- 'write'
$\boldsymbol{a}$-c'er-ineb-s 'makes s.o. write'

(23) Malayalam (Dravidian): -CC vs. -(pp)ikk- (Asher \& Kumari 1997: 276-277)
a. muruk-'be tight' murukk- 'tighten'
b. koll- 'kill' koll-ikk- 'make s.o. kill' 
(24) Guaraní: $m(b) o$ - vs. -uka (Velázquez-Castillo 2002)
a. ngakua 'be big'
mo-ngakua 'make big'
b. mopoti 'clean (tr.)'
mopoti-uka 'make s.o. clean s.th.'

(25) Creek (Muskogean): -ic vs. -ipoyc (Martin 2000: §6.7)
a. asl-
'go out (fire)'
asl-i ${ }^{\circ}$
'put out (fire)'
b. aweyk- 'throw'
aweyk-ipoyc 'make s.o. throw'

(26) Mandinka (Mande): -ndi vs. -rindi (Creissels 2015: §5.2) $)^{13}$
a. nóo-
'get dirty'
nó-ndi
'make dirty'
b. dómó- 'eat'
dómó-ríndí 'make s.o. eat'

In all these cases, the longer causative marker $(\operatorname{lgC})$ is used with transitive bases, while the shorter causative marker ( $\mathrm{shC}$ ) is used with intransitive bases. This generalization was noted by Nedjalkov \& Sil'nickij (1969: 27), who formulated the following generalization:

\section{Universal 8}

If a language has several causative markers of different lengths, then the longer markers tend to be used with transitive bases, and the shorter markers tend to be used with intransitive bases.

In another type of language, the choice between the two markers is conditioned by the distinction between unergatives and unaccusatives. Examples are given in (28)-(31), where the (a) examples have an unaccusative base, and the (b) examples have an unergative base. ${ }^{14}$

(28) Halkomelem (Suttles 2004: 234-237)
a. mé?
'come off'
mér $-x$
'take off'
b. Pimax
'walk'
Píməx-stox $\boldsymbol{x}^{w}$ 'make s.o. walk'

(29) Japanese (Shibatanai \& Pardeshi 2002: §2.1)
a. kawak
'dry (intr.)'
kawak-as- 'dry (tr.)'
b. hasir- 'run'
hasir-ase- 'make s.o. run'

(30) Amharic: $a$ - vs. as- (Amberber 2000: \$3.1)
a. k'allat'a 'melt (intr.)'
a-k'allat'a 'melt (tr.)'
b. č’’ffara 'dance'
as-č’’ffar 'make s.o. dance'

${ }^{13}$ Creissels notes that $-r i$ - is the antipassive marker in Mandinka, so it may seem that a verb first needs to be intransitivized before it can be causativized (see also Malchukov 2016: $\$ 3$ for related phenomena and further discussion). From the current perspective, it is irrelevant whether one adopts this description, because all that matters is that the length difference between 'eat' and 'make eat' is greater than the length difference between 'get dirty' and 'make dirty'.

${ }^{14}$ In some Athapaskan languages, the situation seems to be similar: "In Athapaskan languages, for example, the alternation is marked in the simplest manner, by choice of the so-called 'classifier'..., while the transitivization of unergative verbs like 'walk' and 'run' involves not only this classifier element but special causative prefix morphology as well” (Hale \& Keyser 1987: 25). (See also Rice (2000) on valency-changing constructions in Athapaskan languages.) 
(31) Latvian (Nau 2015: 108-109)
a. kals-t
'dry (intr.)'
kalt $-\bar{e}-t$
'dry (tr.)'
b. danc-o-t 'dance'
danc-in- $\bar{a}-t$
'make s.o. dance'

We can thus venture the following claim, on the analogy of Universal 8:

(32) Universal 9

If a language has several causative markers of different lengths, then the longer markers tend to be used with unergative bases, and the shorter markers tend to be used with unaccusative bases.

The two additional types discussed in the present section i.e. the type of Georgian (etc.) and the type of Halkomelem (etc.) can be represented as in Table 4, using the abbreviated labels "lgC" for long synthetic causatives and "shC" for short synthetic causatives.

Table 4: Synthetic causatives: Some language types $(\mathrm{shC}=$ short synthetic causative, $\operatorname{lgC}=$ long synthetic causative)

\begin{tabular}{cccc}
\hline & $\begin{array}{c}\text { Transitive } \\
\text { ('cut') }\end{array}$ & $\begin{array}{c}\text { Unergative } \\
\text { ('talk') }\end{array}$ & $\begin{array}{c}\text { Unaccusative } \\
\text { ('freeze; break') }\end{array}$ \\
\hline Tuvan & $\mathrm{C}$ & $\mathrm{C}$ & $\mathrm{C}$ \\
Indonesian & $(\mathrm{anaC})$ & $\mathrm{C}$ & $\mathrm{C}$ \\
O'odham & $(\mathrm{anaC})$ & $(\mathrm{anaC})$ & $\mathrm{C}$ \\
Georgian & $\operatorname{lgC}$ & $\mathrm{shC}$ & $\mathrm{shC}$ \\
Halkomelem & $\lg$ & $\operatorname{lgC}$ & $\mathrm{shC}$ \\
\hline (unattested) & $\mathrm{shC}$ & $\operatorname{lgC}$ & $\mathrm{anaC}$ \\
(unattested) & $\operatorname{lgC}$ & $\mathrm{anaC}$ & $\mathrm{shC}$ \\
(unattested) & $\mathrm{anaC}$ & $\mathrm{shC}$ & $\lg \mathrm{\ldots}$ \\
\hline
\end{tabular}

A notable length difference is also found in Levshina's (2016) (in this issue) cross-linguistic study, though Levshina's focus is on contrasting markers for direct vs. indirect causation. But since causatives of unergatives and transitives must express indirect causation (almost by definition), and only causatives of unaccusatives can express direct causation, de facto Levshina's findings are quite comparable with the current generalizations. ${ }^{15}$

Universals 8 and 9 do not at first sight appear parallel to Universals 6 and 7, but one could formulate Universals $6^{\prime}$ and $7^{\prime}$ as follows:

Universals $6^{\prime}-7^{\prime}$

If a language has an analytic and a synthetic causative, then the analytic causative

${ }^{15}$ I have nothing to say here about length differences between direct and indirect causatives formed from the same base verb, e.g. Nivkh t'e-u- [dry-CAus] 'dry s.th.' vs. t'e-gu- [dry-CAus] 'let s.th. dry (tr.)'. But Levshina's explanation of this effect is fully compatible with mine, as seen in $\S 8.2$ below. 
tends to be used with transitive/unergative base meanings, and the synthetic causative with intransitive/unaccusative verb meanings, respectively.

These universals are equivalent to Universals 6 and 7, but as I said earlier, all languages have analytic causatives (on the definition adopted here), so it would be odd to formulate the antecedent of the implication in the way it is done in (33). Nevertheless, (33) shows that Universals 8 and 9 are very similar to Universals 6 and 7, and all follow from Universals 1 and 2 .

\subsection{Lehmann's (2016) implicational claim}

Lehmann (2016: 927) formulates a very similar implicational scale, reproduced (with small changes) ${ }^{16}$ in (34).

(34) base predicate hierarchy for causativization

multivalent $>$ transitive $>$ unergative $>$ unaccusative $>$ adjective

This scale is different from the spontaneity scale in (2) in that it adds "multivalent" at the top and "adjective" at the bottom, and it lacks the distinction between automatic and costly unaccusatives. Moreover, it lacks the (admittedly marginal) class of agentful verb meanings. It is not quite clear what Lehmann's claim is based on (he only refers to Dixon 2000), and since I do not have enough data on a distinction between multivalent and transitive verbs, I will not consider this difference further (see note 8).

On the basis of (34), Lehmann makes the universal claim in (35).

(35) If a strategy forms causative constructions from bases at some point on the base predicate hierarchy in (34), then it forms causative constructions from bases to the right of that point. (Lehmann 2016: 927)

This claim is quite similar to Universals 3, 6 and 7, but it is stronger in that it implies that causativization strategies are fully productive. This is sometimes the case, but by no means always. While English make causatives can be formed with all base verbs (though they sound a bit odd with costly intransitives such as change: ?I made it change), analytic causatives are often unavailable if a synthetic causative exists. For example, Shibatani \& Pardeshi (2002: 93) note that Marathi allows the counterpart of 'Ram drowned Sham' (using a synthetic causative), but not the counterpart of 'Ram made Sham drown' (using an analytic causative). Moreover, synthetic causatives often fail to occur when the language has root transitives for causals (and anticausatives for the noncausal counterparts), as already discussed in connection with the first version of Universal 7 in (20). Thus, while my claims in Universals 1 and 2 (as well as Universals 3-9, which are special cases of these) are somewhat weaker, this is correct and Lehmann's claim in (35) is too strong.

${ }^{16}$ Lehmann uses "active intransitive" for my unergative, and "inactive intransitive" for my unaccusative. (See note 1 for the terminology). 
Lehmann's scale in (34) adds adjectives at the bottom, thus implying that causatives of adjectives (or maybe more generally causatives of state/property words) are formed more readily than causatives of dynamic unaccusative verbs. This receives some support from European languages like English and German, ${ }^{17}$ but I do not have enough data from other languages to know whether it is a world-wide trend.

\section{Causatives and anticausatives}

While the distinction between analytic and synthetic causatives, and between longer and shorter causatives, is primarily relevant at the top of the spontaneity scale, the scale also describes a regularity within unaccusative base verbs (first noted by Croft 1990): Automatic noncausal verbs are more likely to have a causative counterpart, while costly noncausal verbs are more likely to be anticausatives, with a causal basic verb as their counterpart.

The general tendency is illustrated by the verb pairs in (36) and (37).

automatic verb meanings

a. 'melt'

French

Arabic

Hindi-Urdu

Hungarian

Lezgian

b. 'wake up' Finnish

Lithuanian

Mongolian

Turkish

Udmurt noncausal

(basic verbs)

fondre

saaha

pighal-

olvad-

c'ur-un

herä-tä

pabus-ti

ser-ex

uyan-mak

sajka-ny

noncausal

(anticausative verbs) (basic verbs)

a. 'break'

Armenian

Hebrew

Japanese

Romanian

Turkish

b. 'open' Arabic

Finnish

French

Swahili

Udmurt jard-v-el

$n i-s ̌ b a r$

war-e-ru

se rupe

kır-ll-mak

in-fataha

ava-utu-a

s'ouvrir

fungu-k-a

ust-iśky-ny causal

jard-el

šavar

war-u

rupe

kır-mak

fataha

ava-ta

ouvrir

fungu-a

usty-ny causal

(causative verbs)

faire fondre

sayyaha

pighl-aa-

olvasz-t-

c'uru-r-un

herät-tä-ä

pabud-in-ti

sere-e- $x$

uyan-dir-mak

sajka-ty-ny

${ }^{17}$ English and German have many causatives of adjectives (e.g. en-large/ver-größern, black-en/schwärzen, hard-en/härten), but not of unaccusative verbs (except marginally; see Plank \& Lahiri 2015 for discussion). 
As described in Haspelmath (1993) (and discussed further in Kulikov (1998b) and Comrie (2006)), the distinction between automatic and costly verb meanings is by no means clear-cut. There is no clear semantic basis for the distinction, ${ }^{18}$ and it came up only after the pattern in (36)-(37) was observed in a probabilistic fashion. The automatic/costly distinction is thus different from the unergative/unaccusative distinction, and from the transitive/intransitive distinction, but it is treated in the same way in this paper because of the predictions that can be made if it is included (in an idealized way) in the spontaneity scale. ${ }^{19}$ It is important to keep in mind that the predictions here are meant to be probabilistic, i.e. there is no claim that any particular verb should behave in the expected way.

As noted by Haspelmath (1993: §6), different languages have different propensities for using causatives or anticausatives. Languages like Russian, which are anticausative-prominent, tend to have anticausatives also for automatic verb meanings (e.g. rasplavit'-sja 'melt (intr.)'). And languages like Indonesian, which are causative-prominent, tend to have causatives also for costly verb meanings (e.g. me-matah-kan 'break (tr.)'). Languages like Udmurt are intermediate, with an equal number of causatives and anticausatives.

We can thus make the implicational claim in (38).

\section{Universal 9}

If a language generally has causatives of costly base verbs, then it also generally has causatives of automatic verbs (and all base verbs higher on the spontaneity scale).

The distribution of causatives and anticausatives is illustrated in Table 5, where "caus" generalizes over all kinds of causatives (anaC, $\operatorname{lgC}$, shC).

Table 5: Causatives and anticausatives: Some language types (caus = causative, analytic or synthetic, anticaus $=$ anticausative)

\begin{tabular}{|c|c|c|c|c|}
\hline & $\begin{array}{c}\text { Transitive } \\
\text { ('cut') }\end{array}$ & $\begin{array}{l}\text { Unergative } \\
\text { ('talk') }\end{array}$ & $\begin{array}{l}\text { Automatic } \\
\text { ('freeze') }\end{array}$ & $\begin{array}{c}\text { Costly } \\
\text { ('break') }\end{array}$ \\
\hline Russian & caus & caus & anticaus & anticaus \\
\hline Udmurt & caus & caus & caus & anticaus \\
\hline Indonesian & caus & caus & caus & caus \\
\hline (unattested) & caus & caus & anticaus & caus \\
\hline (unattested) & caus & anticaus & caus & caus \\
\hline
\end{tabular}

18 Note especially that the distinction is different from the distinction between INTERNALLY CAUSED VERBS and EXTERNALly CAUSED VERBS that is made by Levin \& Rappaport Hovav (1995) and subsequent studies (e.g. Wright 2001). An internally caused verb (such as 'rust' or 'rot') is one that is conceived of as normally happening without any external cause, while an externally caused verb (such as 'melt', 'wake up', 'break' and 'open') is one that can easily be seen as due to an external cause. With internally caused verbs, causatives are unexpected and sound odd (cf. ?? They made the apples rot).

19 A reviewer points out that similar distinctions were discussed by Howard (2001). 
In fact, since the availability of causatives is more and more restricted as we go down the spontaneity scale, the claim can be made more general, not referring specifically to the distinction between automatic and costly verbs:

\section{(39) Universal 10}

If a language has causatives of any kind of base verb, then it also has causatives of all base verb types higher on the spontaneity scale.

This claim is not much stronger than Universal 9, because the only kind of base verb that is lower on the scale is the agentful type ('be cut'), which is found very rarely. Nevertheless, the formulation in (39) makes it easier to see that the generalization is just a special case of Universal 1: Recall that this claim says that verb meanings higher on the spontaneity scale tend to have longer causative markers the causal verbs, if it has any. This entails that causal verbs whose noncausal counterpart is lower on the scale tend to lack causative markers entirely, thus being either labile, or having an anticausative noncausal counterpart.

We can also turn Universal 10 around and make a claim about anticausatives, which are less restricted with meanings lower on the spontaneity scale:

(40) Universal 11

If a language has anticausatives of any kind of base verb, then it also

has anticausatives of all base verb types lower on the spontaneity scale.

This generalization is not vacuous when it comes to agentful verb meanings, because these are usually expressed by passives, in languages that have them, and passives are of course a kind of anticausative (by the definition used in this paper). ${ }^{20}$ For example, even causative-prominent languages like Indonesian do not have causatives to express the causal counterparts of agentful meanings (i.e. 'cut' is not expressed as 'make s.th. be cut'). Table 6, which includes all five meanings on the scale, shows the fuller picture.

Table 6: Causatives and anticausatives: Some language types (caus $=$ causative, analytic or synthetic, anticaus $=$ anticausative)

\begin{tabular}{cccccc}
\hline & $\begin{array}{c}\text { Transitive } \\
\text { ('cut') }\end{array}$ & $\begin{array}{c}\text { Unergative } \\
\text { ('talk') }\end{array}$ & $\begin{array}{c}\text { Automatic } \\
\text { ('freeze') }\end{array}$ & $\begin{array}{c}\text { Costly } \\
\text { ('break') }\end{array}$ & $\begin{array}{c}\text { Agentful } \\
\text { ('be cut') }\end{array}$ \\
\hline Russian & caus & caus & anticaus & anticaus & anticaus \\
Udmurt & caus & caus & caus & anticaus & anticaus \\
Indonesian & caus & caus & caus & caus & anticaus \\
\hdashline (unattested) & caus & caus & anticaus & caus & anticaus \\
(unattested) & caus & caus & caus & anticaus & caus \\
\hline
\end{tabular}

${ }^{20}$ In the original definition (Nedjalkov \& Sil'nickij 1969; Haspelmath 1987), passives are not anticausatives, because they involve an expressible agent. In this paper, I use a somewhat looser definition, because I do not want to introduce yet another term for a very closely related concept. 
Of course, just as Universal 10 is a special case of Universal 1, Universal 11 is a special case of Universal 2. For causatives, we did make reference to the analytic/ synthetic distinction as well as to the long/short distinction earlier. If anticausatives behave truly like the mirror image of causatives, as implied by the symmetry of Universal 1 and 2, one might expect them to show length differences and/or analyticity differences as well.

And in fact, we do find both of these differences, though not as nicely separated as with causatives. In general, in languages that have both ordinary anticausatives (with unaccusative meanings of the noncausal member) and passives, the passive markers tend to be longer and more analytic. For example, in Russian, the costly causal verb slomat' 'break' has the noncausal counterpart slomat'-sja. By contrast, the agentful causal verb narezat' 'cut' has the noncausal counterpart byt' nareza-nnym, which has both the passive suffix $-n n(y m)$ and the analytic marker byt' (auxiliary 'be'). Of course, passives of verbs like 'cut' are not normally regarded as "periphrastic anticausatives", but if one puts them in the context of the present paper, and in particular the highly general Universals 1 and 2 , then it makes good sense to see them in this way.

\section{Absolute cut-off points}

So far we have seen relative generalizations that basically say that the coding scale of (8a) (repeated here) is in correspondence with the spontaneity scale in (8b), in such a way that causatives (particularly analytic and long ones) occur with higher meanings on the spontaneity scale, while anticausatives (particularly analytic ones, i.e. passives) occur with the lower meanings on the scale.

a. anaC $>\operatorname{lgC}>\operatorname{shC}>$ labile $>\mathrm{A}>$ anaA

b. transitive $>$ unergative $>$ automatic $>$ costly $>$ agentful

This restricts the possibilities, but it still allows a large number of possible types, e.g. all those in Table 7.

Table 7: Causative/anticausative patterns allowed by Universals 1 and 2

\begin{tabular}{cccccc}
\hline & $\begin{array}{c}\text { Transitive } \\
\text { ('cut') }\end{array}$ & $\begin{array}{c}\text { Unergative } \\
\text { ('talk') }\end{array}$ & $\begin{array}{c}\text { Automatic } \\
\text { ('freeze') }\end{array}$ & $\begin{array}{c}\text { Costly } \\
\text { ('break') }\end{array}$ & $\begin{array}{c}\text { Agentful } \\
\text { ('be cut') }\end{array}$ \\
\hline type 1 & anaC & $\operatorname{lgC}$ & shC & labile & A \\
type 2 & anaC & anaC & anaC & anaC & anaA \\
type 3 & anaC & anaC & anaC & lgC & shC \\
type 4 & shC & labile & labile & labile & labile \\
type 5 & A & A & A & A & anaA \\
type 6 & anaC & C & C & C & C \\
\hline
\end{tabular}


It seems that of these types, only the first one is attested. This is because in addition to the relative constraints of Universals 1 and 2, languages are also subject to absolute constraints. These are not different in kind, but can be related to the same basic principles. It is just that these principles sometimes make a particular kind of coding so unlikely that it never occurs. The observed cut-off points are summarized in (41), and each of them is discussed further below.

(41) Universals 11a-d: absolute cut-off points for causatives, labile verbs and anticausatives

a. Analytic causatives occur only as far down the scale as automatic meanings.

b. Anticausatives occur only as far up the scale as automatic meanings.

c. Labile verbs occur only as far up the scale as automatic meanings.

d. (Synthetic) causatives occur only as far down the scale as costly meanings.

First, it appears that no language allows analytic causatives for costly or agentful meanings (cf. 41a). In other words, no language says 'make s.o. break s.th.' to express 'break (tr.)', let alone 'make s.th. be cut' for 'cut'. Analytic causatives only go as far down as automatic meanings. For example, French has faire fondre for 'melt (tr.)' (see 36a above). They are quite uncommon with unaccusative meanings, but within the unaccusatives, they seem to be restricted to automatic meanings.

Second, (almost) no language allows anticausatives for unergative (let alone transitive) meanings (cf. 41b). In other words, no language says 'be made to talk' to express 'talk', let alone 'be made to cut' to say 'cut'. Anticausatives only go as far up as unaccusative meanings, not only costly, but also automatic (though they are much less common with these). For example, Russian has rasplavit'-sja for 'melt (intr.)'. An exceptional case of a language that has an anticausative for an unergative verb is Macedonian, where 'laugh' is literally 'make oneself laugh' (as noted by Nedjalkov 1969). Such anticausatives are extremely rare, so (41b) is still formulated as an absolute cut-off point.

Third, almost no language allows labile verbs for meanings higher than automatic (cf. 41c). Unergatives such as 'talk', 'work' or 'walk' are almost never labile, with additional causal meanings 'make s.o. talk', 'make s.o. work' or 'make s.o. walk'. English is exceptional in that it allows causal meaning with a few unergative verbs (The rider jumped the horse over the fence; The general marched the soldiers to their tents) ${ }^{21}$ but the pattern does not seem to be productive even in English..$^{22}$ In the European languages, labile verbs are generally not used for agentful meanings either (i.e. labile verbs never mean 'cut' and 'be cut'), but there seem to be quite a few languages elsewhere where such labile verbs are common (especially in African languages, e.g. in Mandinka, where

${ }^{21}$ See, for instance, Dixon (1991: 291-293) and Levin \& Rappaport Hovav (1995: 111) for discussion.

${ }^{22}$ When unergatives occur in both intransitive and transitive use, without any valency marker, the transitive use is generally of the "applicative" sort ('laugh at', 'work on', 'walk to', 'look at', and so on). See Kazenin (1994) for exemplification from Yupik and insightful parallels between labile verb pairs and causative/ applicative verb pairs (see also note 12). 
transitive verbs can be used in a passive-like construction without any coding). ${ }^{23}$ Thus, labile verbs actually have the same cut-off behavior as anticausatives.

Finally, almost no language allows causatives for causal counterparts of agentful meanings (cf. 41d). In other words, languages almost never say 'make something be cut' for 'cut'. The only language family where a few causative pairs of this type are attested is Salishan, as discussed by Davis (2000) (e.g. Lillooet $P u \check{s}$ 'get thrown out, causative $P u \check{s}-\check{c}$ 'throw out'; $q$ 'wal 'be cooked', causative $q$ 'wa'l-an 'cook'; Davis 2000: $\$ 4.1$; see also Suttles 2004: 227 for Halkomelem).

Given these absolute cut-off points, we can now say why types 2-6 in Table 7 are never found: Type 2 violates (41a) (analytic causatives go down to costly, one step further than allowed); type 3 violates (41d) (causatives go down to agentful, one step further than allowed); type 4 violates (41c) (labiles go up to unergative, one step further than allowed); type 5 violates (41b) (anticausatives go up to transitive, two steps further than allowed); and type 6 again violates (41d) (causatives go down to agentful).

As far as I can tell, Universals 1 and 2 and the cut-off points of Universal 11 correctly and exhaustively describe the universals of causative verb formation that can be characterized in terms of the meanings on the spontaneity scale and for which we have good evidence (Universals 3-10 are merely special cases of Universals 1 and 2, as discussed in \$5-6). Table 8 gives examples of five concrete languages and their coding patterns, as distributed on the spontaneity scale. ${ }^{24}$

Table 8: Five language types exemplified with concrete languages

\begin{tabular}{cccccc}
\hline & $\begin{array}{c}\text { Transitive } \\
\text { ('cut') }\end{array}$ & $\begin{array}{c}\text { Unergative } \\
\text { ('talk') }\end{array}$ & $\begin{array}{c}\text { Automatic } \\
\text { ('freeze') }\end{array}$ & $\begin{array}{c}\text { Costly } \\
\text { ('break') }\end{array}$ & $\begin{array}{c}\text { Agentful } \\
\text { ('be cut') }\end{array}$ \\
\hline English & anaC & anaC & labile & labile & anaA \\
German & anaC & anaC & labile & A & anaA \\
Latvian & $\operatorname{lgC}$ & $\operatorname{lgC}$ & $\mathrm{shC}$ & $\mathrm{A}$ & anaA \\
Japanese & $\operatorname{lgC}$ & $\operatorname{lgC}$ & $\mathrm{shC}$ & $\mathrm{A}$ & $\mathrm{A}$ \\
Indonesian & $\mathrm{anaC}$ & $\mathrm{C}$ & $\mathrm{C}$ & $\mathrm{C}$ & anaA \\
\hline
\end{tabular}

It may well be possible to find even stricter generalizations by invoking additional comparative concepts (e.g. productive vs. unproductive causatives, or different kinds of base meanings), but in this paper, I will not pursue ideas of this kind any further. Instead, the next section will address the question of explanation.

${ }^{23}$ See Cobbinah \& Lüpke (2009), Creissels (2015: §4.2), as well as Haspelmath \& APiCS Consortium (2013) on "passive without verbal coding" in 29 pidgin and creole languages.

${ }^{24}$ I know of no language that has more than four different coding types for causal-noncausal verb pairs, i.e. I know no language that is like type 1 in Table 7. Maybe this is another kind of absolute restriction: More diversity than this would be too much and languages never do this. I do not know why this should be so, so I assume that this is just an accidental gap. 


\section{Explanation in terms of predictability}

As already mentioned in the first section of this paper, I propose that Universals 1 and 2 and 11a-d can be explained through the universal preference for frequently occurring and predictable information to be coded by short forms: Coding asymmetries reflect asymmetries of predictability. But before getting to the main point in $\S 8.2$, I need to address the issue of how to think of "analytic" forms.

\subsection{Why do "analytic" and long forms behave similarly?}

The two key universals of $\S 4$ make the prediction that (anti)causative forms will be "longer and more analytic" under certain conditions. Why is it that formal length and analyticity are conditioned by the same factors?

I propose that the answer is very simple: Short forms tend to be "synthetic", and long forms "analytic", for independent reasons that have little to do with predictability. Thus, what needs to be explained in the present context is only that certain kinds of (anti) causatives are coded by longer forms, not that they also tend to be "analytic".

Linguists do not often talk about the correlation between analyticity/syntheticity and length/shortness of grammatical markers, but the facts are well-known to every linguist: Tense-aspect auxiliaries (analytic) tend to be longer (in terms of phonological segments) than tense-aspect affixes (synthetic) (e.g. English will, have vs. -ed, -ing), and adpositions (analytic) tend to be longer than case affixes (synthetic) (e.g. Latin cum, per vs. -i, -ae). There are few published works documenting this tendency, ${ }^{25}$ but I have no doubt that it is very robust.

However, testing this claim is not straightforward (and perhaps impossible), because there are diverse properties of grammatical markers that are associated with the concepts of "syntheticity" (or single wordhood) and "analyticity" (or multiple wordhood), and it is quite unclear whether these properties themselves correlate significantly with each other (Haspelmath 2011b). In fact, in Haspelmath (2018b), I observe that while the notion of (diachronic) ANALYTICIZATION is well-defined and clear, the notion of analyticity is not clear, even though some linguists may have intuitions about it. (For this reason, I use these terms in quotation marks in this subsection.) There does seem to be a general tendency for COALESCENCE along a range of different parameters in the course of grammaticalization (Haspelmath 2011a), but we are presently unable to make this idea precise. Thus, if someone pressed me about defining "analyticity" for the purposes of Universals 1 and 2, I would retreat to saying that "analytic" can be dropped from these definitions (or it could simply be defined in orthographic terms). I use the term in this paper because the difference between (orthographically) "analytic" and "synthetic" causatives is so salient in the literature, and I wanted to preserve as much continuity with the earlier literature as possible. However, I suspect that if we left out all reference to "analytic" in

${ }^{25}$ I can only think of Bybee et al. (1994: Chapter 4), where it is shown that older perfective/past-like tense-aspect forms tend to be both shorter and more fused (i.e. less analytic). 
Universals 1 and 2, and only talked about length of markers, little or nothing would be lost (for example, I am not aware of a language where analytic and synthetic causative markers differ only in analyticity, not in segmental length).

\subsection{Why are causative markers longer when the base verb is more spontaneous, and why are anticausative markers longer when the base verb is less spontaneous?}

Now we get to the main point of this section: The explanatory proposal of this paper is that Universals 1 and 2 are special cases of form-frequency correspondence, as formulated in (42) (Haspelmath et al. 2014; Haspelmath 2018a).

(42) The grammatical form-frequency correspondence hypothesis

When two minimally different grammatical patterns (i.e. patterns that form an opposition) occur with significantly different frequencies, the less frequent pattern tends to be overtly coded (or coded with more coding material), while the more frequent pattern tends to be zero-coded (or coded with less coding material).

As explained in greater detail in the work cited, the fundamental observation is that language structure is the result of a compromise or trade-off between the two competing forces of speaker parsimony (ease of production, least effort of coding) and hearer transparency (clarity, robust information transmission). If an aspect of the utterance content is expected or predictable, less coding effort needs to be expended by the speaker, and this can become part of the grammatical systems of languages. In grammatical oppositions, such as singular/plural, nominative/accusative, present/future, inalienable/alienable possession, attributive/predicative adjectives, the more frequently used meanings are generally coded with less material, because they are more expected or predictable (in the typological literature, these asymmetries are sometimes treated under the heading of "markedness", e.g. Croft 2003: Chapter 4).

Universals 1 and 2 (and Universals $11 \mathrm{a}-\mathrm{d})^{26}$ can be subsumed under the form-frequency explanation if it can be made plausible that causal meanings are more frequent and hence more expected for base meanings lower on the spontaneity scale, and if noncausal meanings are more frequent and more expected for base meanings higher on the spontaneity scale. Thus, we should have increasing frequency of the kinds of meanings in (43) (causal counterparts of the meanings on the spontaneity scale; the " $<$ " symbol means 'less frequent than').

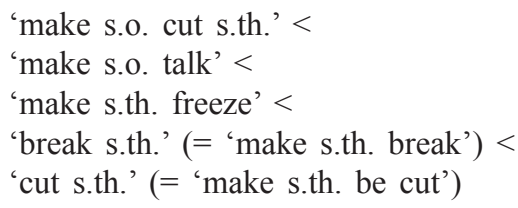

${ }^{26}$ The precise cut-off points are not explained by form-frequency correspondence, but it is expected that such cut-off points exist and can be described in terms of the spontaneity scale. 
Conversely, we should have decreasing frequency of the kinds of meanings in (44) (the noncausal meanings on the spontaneity scale; ">" means 'more frequent than').

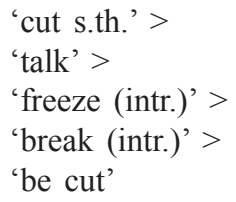

The relevant frequencies here are of course relative frequencies within the opposition, i.e. when I say that 'make s.o. cut s.th.' is less frequent than 'make s.o. talk', I mean that the proportion of causal occurrences of all relevant occurrences, whether causal or noncausal, is lower with 'cut' than with 'talk' (or rather, more generally, it is lower with transitive verbs than with unergative verbs), lower with 'talk' than with 'freeze', and so on.

If the frequency distributions of the verb pairs are more or less as in Table 9, then I take the form-frequency explanation as well-supported.

Table 9: Expected frequency distributions for the five types on the spontaneity scale

\begin{tabular}{llrlr}
\hline & CAUSAL & \multicolumn{3}{c}{ NONCAUSAL } \\
\hline transitive & 'make cut' & $0.5 \%$ & 'cut' & $99.5 \%$ \\
unergative & 'make talk' & $5 \%$ & 'talk' & $95 \%$ \\
automatic & 'make freeze' & $40 \%$ & 'freeze' & $60 \%$ \\
costly & 'break (tr.)' & $70 \%$ & 'break (intr)' & $30 \%$ \\
agentful & 'cut' & $99.5 \%$ & 'be cut' & $0.5 \%$ \\
\hline
\end{tabular}

The frequency distinction between transitive and unergative causatives should be easy to demonstrate on the basis of corpus data from languages like English or French, and the frequency distinction between unergatives and unaccusatives should even be intuitively clear. I will not cite any actual frequency data from corpora here, leaving a demonstration of the hypothesized frequency distributions to future work.

The distinction between automatic and costly verb meanings (within the unaccusative class) is much less obvious, and as mentioned in $\S 2$, the two types were introduced primarily for expository purposes and for cross-linguistic comparison, and there is in fact a continuum (no language seems to make a clear-cut and productive distinction between the two types). Thus, it is expected that it will be more difficult to demonstrate a frequency difference, but Haspelmath et al. (2014) found a significant correlation between the relative frequency of causal occurrences and the degree to which languages prefer anticausative coding. Automatic verb pairs like 'freeze' and 'melt' show between 50\% and $70 \%$ noncausal occurrences, while costly verb pairs like 'break' and 'open' show between $20 \%$ and $40 \%$ noncausal occurrences (on average in the seven languages for which corpus data were examined). 
That agentful noncausals are very rare, compared to costly unaccusative noncausals, should be clear without much corpus work (note that English passives do not really count, because they merely change the perspective and do not eliminate the agent; strictly speaking, one would have to examine the frequency of English expressions such as undergo cutting).

To summarize the form-frequency explanation in non-technical terms: Meanings higher on the spontaneity scale tend to require longer (and more analytic) causative markers because it is less common (and hence less expected) that one uses them in a causal context, so the speaker needs to make a greater coding effort to signal the causal meaning to the hearer. Conversely, meanings lower on the scale tend to have anticausative markers because it is less common and less expected to find them in a noncausal context, so speakers need to expend coding energy to signal the noncausal meaning. These speaker and hearer needs tend to be conventionalized in languages as coding asymmetries. The explanation thus has nothing to do with any semantic notion of "spontaneity" - the only role of this term is to provide a transparent label for the scale, as a basis for formulating the universals.

The fact that Universals 1 and 2 are mirror images of each other is thus a natural consequence of the predictability explanation. We find similar mirror-image patterns in other domains such as adpossessive marking (Haspelmath 2017) and singulative/plurative marking (Haspelmath \& Karjus 2017).

Levshina's (2016) (in this issue) study of contrasting causative markers in 46 unrelated languages arrives at results that are fully compatible with the present findings: Markers of indirect causation (which include causatives of transitive and unergative verbs) tend to be longer, more productive, more autonomous, and more distant from the base than markers of direct causation. Levshina likewise attributes this to the fact that markers of direct causation are more frequent and more expected than markers of indirect causation.

Overall, I regard the form-frequency explanation of the universals observed in this paper as very successful. And while the bulk of the previous literature on causatives ignores frequency of use and focuses entirely on meaning, I need to acknowledge that the appeal to frequency is not quite novel. In fact, the very first systematic study of causatives in the literature, Nedjalkov \& Sil'nickij's seminal study from 1969, observes the frequency asymmetry:

Note in this connection the much higher frequency of situations representing causatives from intransitives (like 'burn (something)') than situations representing causatives from transitives (like 'make (someone) burn (something)') (Nedjalkov \& Sil'nickij 1969: 26, my translation) ${ }^{27}$

Another author who hints at a role for frequency is Dixon (2000: 65). He notes in connection with 'drink' and 'eat' as base verbs (see the last paragraph of §5.1) that "it seems that drinking and eating are the transitive activities which people are most likely to make other people do, on every continent." Likelihood is of course the same as frequency of occurrence in the world, and this can be expected to correlate with linguistic frequency.

27 “В этой же связи следует отметить гораздо бо́льшую частотность ситуаций, отображаемых $\mathrm{V}^{\mathrm{j}}$ от $\mathrm{V}^{\text {in }}$ (типа ‘сжечь'), чем ситуаций, отображаемых $\mathrm{V}^{\mathrm{j}}$ от $\mathrm{V}^{\mathrm{tr}}$ (типа ‘велеть сжечь').” 
And most recently, Shibatani (2016: 475) adopts a very similar perspective, when he writes about formal coding in causative and applicative constructions: "A less familiar concept/experience/situation requires formal coding that is equal to or greater in functional transparency than that expressing a familiar concept/experience/situation in the relevant functional domain" (he does not define "functional transparency", but it largely corresponds to length; and he does not define "familiarity", but it largely corresponds to frequency).

\subsection{Alternative explanations}

Of course, frequency and expectedness/predictability are not the only possible explanatory factors relevant to the formation of causative verbs, and before concluding this paper, this subsection discusses a few alternatives.

To begin with, one could doubt the role of frequency, and argue that the greater expectedness of certain kinds of causal and noncausal situations derives from some other factor. One would then agree with the account in $\$ 8.2$ that different degrees of expectedness (or predictability) are responsible for different coding strategies, but one would say that both the frequency asymmetry and the expectedness asymmetry are caused by some other factor (i.e. rather than a causal chain "frequency $>$ predictability $>$ short coding", one would have a causal fork, with some unknown factor causing both predictability (and then short coding) and usage frequency. This is a possibility (also discussed in Haspelmath et al. 2014: §9) that cannot be ruled out easily, but that is also difficult to argue for, because predictability cannot be readily measured. But I do not want to dismiss this possibility.

One possible candidate for this unknown factor could be ease of conceptualization. One might argue that causal situations with a transitive base situation are more difficult to conceptualize, and that this gets progressively easier as one goes down the spontaneity scale. Lehmann's (2016: 926-927) explanation of his scale (see 34 above) can be seen in this light:

Keeping control of a situation gets increasingly difficult in proportion to two factors: the number of participants it contains and the degree of control of the causee. Consequently, semantic complexity of a causative construction increases along these two parameters: An additional higher agent is both more expected and easier to accommodate in a situation the fewer participants this already contains and the less control these already have.

Lehmann goes on to note a correspondence between the structural complexity and "semantic complexity", but does not really explain it. And in the above quotation, it is not clear whether Lehmann is talking about difficulty of conceptualization, or the difficulty of being a causer in a causal situation with a transitive base event. The latter could lead to lower frequency in the world, which could lead to lower usage frequency - so this would again favour the frequency/expectedness explanation. Moreover, it is quite unclear whether an explanation in terms of conceptualization difficulty could extend to meanings lower on the scale, where languages start to use anticausatives.

Dixon (2000: §5) describes a correlation that is similar to the one that we saw in this paper, between degrees of "compactness" of the "causative mechanism" (broadly corre- 
sponding to the coding scale in (8a): anaC $>\lg \mathrm{C}>\operatorname{shC}>$ labile) on the one hand, and various semantic parameters, especially direct vs. indirect causation, volitionality/control of the causee, but also state vs. action and intransitive vs. transitive nature of the noncausal verb (he cites Comrie (1989: 172) and Givón (1990: 556) as predecessors). The scope of Dixon's generalizations is thus much broader than the generalizations discussed in this paper, but he does not attempt an explanation of the correlations, limiting himself to citing Haiman's (1983: 783-788) explanation in terms of iconicity. I have argued against iconicity explanations elsewhere (especially in Haspelmath 2008), ${ }^{28}$ so I will not say anything further here.

But what about the other generalizations that Dixon lists - can they be explained in terms of form-frequency correspondence? I have not investigated them in detail, but it seems to me that my explanation can be extended to them. In particular, direct causation is generally much more frequent than indirect causation, so it is expected that direct causative markers are shorter than indirect causative markers (see also Shibatani 2016: $\S 4$ for some frequency data from Japanese).

Shibatani \& Pardeshi (2002: §5) also discuss the correlation between formal properties of causative markers and certain aspects of meaning, especially the distinction between direct and indirect causation (see also Shibatani 2016 for related ideas). But in contrast to Dixon, they describe the main formal distinction not in terms of "compactness", but in terms of productivity. They note that analytic causatives are typically very productive, and that highly productive "morphological" causatives may express indirect causation, whereas unproductive morphological causatives generally express direct causation, just like root-suppletion causatives (of the die/kill type). But the explanation that they propose again appeals to iconicity, via the notion of transparency (because productive causatives are more transparent):

A higher degree of morphological transparency correlates with a higher degree of separability of elements corresponding to the two event segments constituting a causative situation. Our claim is that this separability of the component elements making up a causative expression correlates with the distinguishability of the causing and the caused event segments making up a causative situation. (Shibatani \& Pardeshi 2002: 115)

Shibatani \& Pardeshi are right that productivity is an additional correlating feature that plays no role in Dixon's "compactness" account, and I have not taken productivity into account in my explanation either (this is a topic for future work). However, they leave the length dimension out of consideration, which I have argued (in §8.1) underlies the analytic/synthetic distinction and thus is the most basic aspect of "compactness" (and Dixon does recognize that length is an aspect of form that correlates with his semantic parameters) ${ }^{29}$

${ }^{28}$ See also Haspelmath et al. (2014: 592-595) (where iconicity is treated under form-meaning complexity isomorphism), and Haspelmath (2017) for form-frequency correspondence in alienable/inalienable possession, another phenomenon that is prominently discussed by Haiman. (Note that I did invoke iconicity in the earlier 1993 paper, but I have since come to recognize that the form-frequency explanation actually solves the problems with iconicity that I addressed unsuccessfully in that early paper.)

29 "Firstly, a shorter affix is more compact than a longer one. Secondly, a causative mechanism which does not lengthen the word ... is more compact than affixation." (Dixon 2000: 75) 
All they say about the correlation between productivity and analyticity is that it "is best understood in terms of historical change" (2002: 113), arguing that a typical change is for a productive causative construction to lose its productivity and narrow down the scope of its application, eventually becoming lexicalized, "driven by the force of grammaticalization" (2002: 14). But the loss of productivity is by no means inevitable or even typical of grammaticalization changes, so "the force of grammaticalization" is not a valid explanation. And causative constructions may not only lose productivity, but they can also become more productive, as has happened, for example, with Indic causatives from the Old Indic period onward (e.g. Kulikov 1993: 148-149).

Whatever the virtues of these competing explanations of the correlation between the forms and meanings of causative markers, they are less general than my explanation in terms of form-frequency correspondence, because they do not explain why languages tend to employ anticausatives lower on the spontaneity scale. As we move from automatic unaccusatives to costly unaccusatives, noncausal occurrences become more frequent than causal occurrences (cf. Table 9), so form-frequency correspondence lets us expect that the coding asymmetry will be reversed, and this is exactly what happens. No semantically based approach that I know of has an explanation for this.

\section{Conclusion}

I conclude that the spontaneity scale coupled with form-frequency correspondence makes correct predictions about some significant cross-linguistic patterns that have often seemed puzzling: In causal-noncausal verb pairs (whether analytic, synthetic, or labile), causatives are more likely and tend to be longer for noncausal meanings high on the spontaneity scale, while anticausatives are more likely for noncausal meanings low on the scale (Universals 1 and 2). For some types of verbs and meanings, the likelihood is so low that they are not found at all, so that we get absolute cut-off points, which are not predicted as such by form-frequency correspondence, but which occur in the expected direction.

In the earlier literature, the correlations have not gone unnoticed (especially for causatives of unaccusatives, unergatives and transitives), but have generally been interpreted in semantic terms, and have been related especially to the contrast between indirect causation (for causatives of unergatives and transitives) and direct causation (for causatives of unaccusatives). My explanation in this paper is more general in that it also accounts for different subtypes of unaccusatives (automatic vs. costly unaccusatives), as well as for the occurrence of anticausatives, which are anti-iconic and unexpected on semantic accounts.

A question that people often ask when confronted with a form-frequency explanation is what causes the frequency asymmeries in the first place, and whether the frequency could not be caused by the semantic distinctions, so that the direction of causation is different. The answer I give is that whatever causes the frequency asymmetries here, elsewhere in grammar, frequency asymmetries clearly have diverse causes. But the results are uniform: In many domains of grammar (and in the lexicon as well), coding asym- 
metries correlate with frequency asymmetries, and the simplest explanation of these highly general patterns is that shorter forms for more frequent (and hence more expected) meanings are an adaptive response to the demands of efficient communication.

Finally, I should make it clear that the spontaneity scale and the explanations proposed in this paper have no immediate consequences for language-particular analyses. I am not proposing that the spontaneity scale should be used in description (as it is a comparative scale, not a descriptive scale, cf. Haspelmath 2015b), and I am not proposing that language-specific descriptions should appeal to frequency. The present paper is about cross-linguistic trends, which are best described in terms of a special set of comparative concepts, and about the (efficiency-based) explanation of these trends. Language-particular systems are a different story and may involve rather different categories and generalizations (recall also note 11 about the antipassive in Mandinka).

\section{Acknowledgements}

The support of the European Research Council (ERC Advanced Grant 670985, Grammatical Universals) is gratefully acknowledged. I also thank the reviewers (among them the competent and meticulous editors), as well as many people who heard me talk about these issues since 2005 and who gave pertinent comments.

\section{References}

Amberber, Mengistu. 2000. Valency-changing and valency-encoding devices in Amharic. In Dixon, R. M. W. \& Aikhenvald, Alexandra Y. (eds.), Changing valency: Case studies in transitivity, 312-332. Cambridge: Cambridge University Press.

Asher, R. E. \& Kumari T. C. 1997. Malayalam. London: Routledge.

Austin, Peter K. 1997. Causatives and applicatives in Australian Aboriginal languages. In Matsumura, Kazuto \& Hayashi, Tooru (eds.), The dative and related phenomena, 165-225. Tokyo: Hituzi Syobo.

Bybee, Joan L. \& Perkins, Revere \& Pagliuca, William. 1994. The evolution of grammar: Tense, aspect and modality in the languages of the world. Chicago: The University of Chicago Press.

Cobbinah, Alexander \& Lüpke, Friederike. 2009. Not cut to fit: Zero coded passives in African languages. In Brenzinger, Matthias \& Fehn, Anne-Maria (eds.), Proceedings of the 6th World Congress of African Linguistics, 153-165. Cologne: Köppe.

Cole, Peter \& Son, Min-Jeong. 2004. The argument structure of verbs with the suffix -kan in Indonesian. Oceanic Linguistics 43(2). 339-364.

Comrie, Bernard. 1975. Causatives and universal grammar. Transactions of the Philological Society 1974. 1-32.

Comrie, Bernard. 1989. Language universals and linguistic typology: Syntax and morphology. Oxford: Blackwell.

Comrie, Bernard. 2006. Transitivity pairs, markedness, and diachronic stability. Linguistics 44(2). 303-318.

Creissels, Denis. 2015. Valency properties of Mandinka verbs. In Malchukov, Andrej L. \& Comrie, Bernard (eds.), Valency classes in the world's languages: A comparative handbook, vol. 1, 221-259. Berlin: De Gruyter Mouton.

Croft, William. 1990. Possible verbs and the structure of events. In Tsohatzidis, Savas L. (ed.), Meanings and prototypes: Studies in linguistic categorization, 48-73. London: Routledge.

Croft, William. 2003. Typology and universals. 2nd edition. Cambridge: Cambridge University Press.

Davis, Henry. 2000. Salish evidence on the causative-inchoative alternation. In Dressler, Wolfgang U. (ed.), Morphological analysis in comparison, 25-60. Amsterdam: Benjamins. 
Dixon, Robert M. W. 1988. A grammar of Boumaa Fijian. Chicago: University of Chicago Press.

Dixon, Robert M. W. 2000. A typology of causatives: Form, syntax and meaning. In Dixon, Robert M.W. \& Aikhenvald, Alexandra Y. (eds.), Changing valency: Case studies in transitivity, 30-83. Cambridge: Cambridge University Press.

Givón, T. 1990. Syntax: A functional-typological introduction. Vol. 2. Amsterdam: Benjamins.

Haiman, John. 1983. Iconic and economic motivation. Language 59(4). 781-819.

Hale, Kenneth L. 2000. A Uto-Aztecan ('O'odham) reflection of a general limit on predicate argument structure. In Casad, Eugene H. \& Willett, Thomas L. (eds.), Uto-Aztecan: Structural, temporal and geographic perspectives: Papers in memory of Wick R. Miller by the friends of Uto-Aztecan, 155-169. Hermosillo: Universidad de Sonora.

Hale, Kenneth L. \& Keyser, Samuel J. 1987. A view from the middle. Cambridge, MA: MITWPL.

Hale, Kenneth L. \& Keyser, Samuel J. 1993. On argument structure and the lexical expression of syntactic relations. In Hale, Kenneth L. \& Keyser, Samuel J. (eds.), The view from Building 20: Essays in linguistics in honor of Sylvain Bromberger. Cambridge, MA: MIT Press.

Haspelmath, Martin \& Karjus, Andres. 2017. Explaining asymmetries in number marking: Singulatives, pluratives and usage frequency. Linguistics, to appear.

Haspelmath, Martin \& the APiCS Consortium. 2013. Passive constructions. In Michaelis, Susanne Maria \& Maurer, Philippe \& Haspelmath, Martin \& Huber, Magnus (eds.), Atlas of Pidgin and Creole Language Structures Online. Leipzig: Max Planck Institute for Evolutionary Anthropology. http://apics-online.info/ parameters/90. (Accessed 2017-02-15.)

Haspelmath, Martin \& Calude, Andreea \& Spagnol, Michael \& Narrog, Heiko \& Bamyac1, Elif. 2014. Coding causal-noncausal verb alternations: A form-frequency correspondence explanation. Journal of Linguistics 50(3). 587-625.

Haspelmath, Martin. 1987. Transitivity alternations of the anticausative type. (Arbeitspapiere des Instituts für Sprachwissenschaft N.F. Nr. 4). Cologne: Universität zu Köln.

Haspelmath, Martin. 1993. More on the typology of inchoative/causative verb alternations. In Comrie, Bernard \& Polinsky, Maria (eds.), Causatives and transitivity, 87-120. Amsterdam: Benjamins.

Haspelmath, Martin. 2008. Frequency vs. iconicity in explaining grammatical asymmetries. Cognitive Linguistics 19(1). 1-33.

Haspelmath, Martin. 2011a. The gradual coalescence into "words" in grammaticalization. In Narrog, Heiko \& Heine, Bernd (eds.), The Oxford handbook of grammaticalization, 342-355. Oxford: Oxford University Press.

Haspelmath, Martin. 2011b. The indeterminacy of word segmentation and the nature of morphology and syntax. Folia Linguistica 45(1). 31-80.

Haspelmath, Martin. 2015a. Transitivity prominence. In Malchukov, Andrej L. \& Comrie, Bernard (eds.), Valency classes in the world's languages: A comparative handbook, vol. 1, 131-147. Berlin: De Gruyter Mouton.

Haspelmath, Martin. 2015b. Descriptive scales versus comparative scales. In Bornkessel-Schlesewsky, Ina \& Malchukov, Andrej L. \& Richards, Marc (eds.), Scales and hierarchies: A cross-disciplinary perspective, 45-58. Berlin: De Gruyter Mouton.

Haspelmath, Martin. 2017. Explaining alienability contrasts in adpossessive constructions: Predictability vs. iconicity. Zeitschrift für Sprachwissenschaft 36(2). 193-231.

Haspelmath, Martin. 2018a. Explaining grammatical coding asymmetries, to appear.

Haspelmath, Martin. 2018b. Revisiting the anasynthetic spiral. In Heine, Bernd \& Narrog, Heiko (eds.), Grammaticalization and language typology, to appear.

Howard, Harry. 2001. Negentropic causation vs. entropic inchoation. In Silva, A.S. (ed.), Linguagem e cognição: A perspectiva da linguística cognitiva, 401-421. Braga: APL/UCP, Faculdade de Filosofia de Braga. (http://semanticsarchive.net/Archive/GiwZjgwO)

Kazenin, Konstantin I. 1994. On the lexical distribution of agent-preserving and object-preserving transitivity alternations. Nordic Journal of Linguistics 17(02). 141-154.

Kulikov, Leonid I. 1993. The "second causative": A typological sketch. In Comrie, Bernard \& Polinsky, Maria (eds.), Causatives and transitivity, 121-154. Amsterdam: Benjamins.

Kulikov, Leonid I. 1998a. Causative constructons in Tuvinian: Towards a typology of transitivity. In Johanson, Lars (ed.), The Mainz Meeting: Proceedings of the Seventh International Conference on Turkic Linguistics, 258-264. (Turcologica 32). Wiesbaden: Harrassowitz. 
Kulikov, Leonid I. 1998b. Passive, anticausative and classification of verbs: The case of Vedic. In Kulikov, Leonid I. \& Vater, Heinz (eds.), Typology of verbal categories: Papers presented to Vladimir Nedjalkov on the occasion of his 70th birthday, 139-154. Tübingen: Niemeyer.

Kulikov, Leonid. 2013. Constraints on the causative derivation in early Vedic: Evidence for a diachronic typology of transitivity. Poznan Studies in Contemporary Linguistics 49(1). 79-101.

Lazard, Gilbert. 2002. Transitivity revisited as an example of a more strict approach in typological research. Folia Linguistica 36(3-4). 141-190.

Lehmann, Christian. 2016. Latin causativization in typological perspective. In Poccetti, Paolo (ed.), Latinitatis rationes: Descriptive and historical accounts for the Latin language, 917-943. Berlin: De Gruyter Mouton.

Levin, Beth \& Rappaport Hovav, Malka. 1995. Unaccusativity: At the syntax-lexical semantics interface. Cambridge, MA: MIT Press.

Levshina, Natalia. 2016. Finding the best fit for direct and indirect causation: a typological study. Lingua Posnaniensis 58(2). 65-82.

Malchukov, Andrej L. 2016. "Ambivalent voice": Markedness effects in valency change. In Kageyama, Taro \& Jacobsen, Wesley M. (eds.), Transitivity and valency alternations: Studies on Japanese and beyond, 389-422. (Trends in Linguistics, Studies and Monographs, 297). Berlin: De Gruyter.

Nau, Nicole. 2015. Morphological causatives in contemporary Latvian. In Holvoet, Axel \& Nau, Nicole (eds.), Voice and argument structure in Baltic, 99-145. Amsterdam: Benjamins.

Nedjalkov, Vladimir P. \& Sil'nickij, Georgij G. 1969. Tipologija morfologičeskogo i leksičeskogo kauzativov [Typology of morphological and lexical causatives]. In Xolodovič, Aleksandr A. (ed.), Tipologija kauzativnyx konstrukcij [Typology of causative constructions], 20-60. Moskva: Nauka. (English translation: Nedyalkov \& Silnitsky 1973)

Nedjalkov, Vladimir P. 1966. Ob areal'nyx universalijax (na materiale kauzativnyx glagolov) [Concerning areal universals (on the material of causative verbs)]. In: Konferencija po problemam izučenija universal'nyx $i$ areal'nyx svojstv jazyka: Tezisy, 55-58. Moskva: Nauka.

Nedjalkov, Vladimir P. 1969. Nekotorye verojatnostnye universalii v glagol'nom slovoobrazovanii. [Some probabilistic universals in verbal word-formation.] In Vardul', I.F. (ed.), Jazykovye universalii i lingvističeskaja tipologija, 106-114. Moskva: Nauka.

Nedyalkov, Vladimir P. \& Silnitsky, Georgy G. 1973. The typology of morphological and lexical causatives. In Kiefer, Ferenc (ed.), Trends in Soviet theoretical linguistics, 1-32. Dordrecht: Reidel.

Nichols, Johanna \& Peterson, David A. \& Barnes, Jonathan. 2004. Transitivizing and detransitivizing languages. Linguistic Typology 8(2). 149-211.

Perlmutter, David M. 1978. Impersonal passives and the unaccusative hypothesis. Proceedings of the 4th Annual Meeting of the Berkeley Linguistics Society, 157-189. Berkeley: Berkeley Linguistics Society.

Plank, Frans \& Lahiri, Aditi. 2015. Macroscopic and microscopic typology: Basic Valence Orientation, more pertinacious than meets the naked eye. Linguistic Typology 19(1). 1-54.

Rice, Keren. 2000. Voice and valency in the Athapaskan family. In Dixon, R.M.W. \& Aikhenvald, Alexandra Y. (eds.), Changing valency: Case studies in transitivity, 173-235. Cambridge: Cambridge University Press.

Shibatani, Masayoshi \& Pardeshi, Prashant. 2002. The causative continuum. In Shibatani, Masayoshi (ed.), The grammar of causation and interpersonal manipulation, 85-126. Amsterdam: Benjamins.

Shibatani, Masayoshi. 2016. The role of morphology in valency alternation phenomena. In Kageyama, Taro \& Jacobsen, Wesley M. (eds.), Transitivity and valency alternations: Studies on Japanese and beyond, vol. 297, 445-478. (Trends in Linguistics, Studies and Monographs). Berlin: De Gruyter.

Song, Jae Jung. 1996. Causatives and causation: A universal-typological perspective. London: Longman.

Suttles, Wayne P. 2004. Musqueam reference grammar. Vancouver: UBC Press.

Velázquez-Castillo, Maura. 2002. Guaraní causative constructions. In Shibatani, Masayoshi (ed.), The grammar of causation and interpersonal manipulation, 507-534. Amsterdam: Benjamins.

Wright, Saundra K. 2001. Internally caused and externally caused change of state verbs. Ph.D. dissertation, Northwestern University. 